\title{
Abnormalities of chest wall motion in patients with chronic airflow obstruction
}

\author{
JJ GILMARTIN, GJ GIBSON \\ From the Regional Cardiothoracic Centre, Freeman Hospital, Newcastle upon Tyne
}

\begin{abstract}
Forty patients with severe chronic stable airflow obstruction and hyperinflation were studied to assess patterns of abnormal chest wall motion and their frequency. Dimensional changes were measured during tidal breathing, four pairs of magnetometers being used to record anteroposterior diameters of ribcage and abdomen and two lateral diameters of the ribcage. Chest wall movements were qualitatively normal in only five patients. Three main types of abnormality were found and 13 subjects had two or more abnormal patterns. Lateral ribcage paradox was present in 31 of the 40 patients and was recognised clinically in all except one. Inspiratory indrawing of the lower sternum was recorded in 12 patients, paradoxical inspiratory motion of the abdomen was present in four patients and in six there was a biphasic expiratory pattern of abdominal movement. Analysis of variance showed no significant group differences in severity of airflow obstruction or hyperinflation between the patients with qualitatively normal motion and those with different types of abnormal motion. Relationships between the tidal displacement of each dimension and severity of airflow obstruction and hyperinflation were examined. In general, patients with more severe hyperinflation showed less abdominal movement and those with more severe airflow obstruction had less lateral expansion of the ribcage, but the correlations were weak. It is concluded that abnormal motion of the chest wall is very common in patients with airflow obstruction and hyperinflation, that clinical recognition of abnormal motion other than lateral ribcage paradox is easily overlooked, and that quantitative relationships between abnormal motion and disease severity are weak.
\end{abstract}

In the normal person during tidal breathing the chest wall expands by displacement of the ribcage and abdomen and this motion is closely related to change in lung volume. In patients with chronic airflow obstruction and hyperinflation various abnormalities of chest wall motion have been reported; the most familiar is paradoxical inspiratory indrawing of the lateral rib margin, which is a well established physical sign of airways obstruction. ${ }^{2}$ Other abnormalities which have been described include paradoxical or incoordinate abdominal motion ${ }^{34}$ and paradoxical inspiratory indrawing of the ribcage in the anteroposterior dimension; ${ }^{5}$ these latter abnormalities have been

Address for correspondence: Dr JJ Gilmartin, Regional Cardiothoracic Centre, Freeman Hospital, Newcastle upon Tyne NE7 7DN. Reprints will not be available.

Accepted 29 November 1983 recorded with magnetometers and other devices, but they are less often recognised as physical signs on clinical examination. We have performed physical examination and dimensional measurements by magnetometry during tidal breathing in a group of patients with chronic airflow obstruction and hyperinflation to assess the patterns and frequency of the various abnormalities and their relationship to the severity of airflow obstruction and hyperinflation. In a subgroup of patients we have also assessed the effect of posture on the presence of paradoxical movement.

\section{Patients and methods}

We studied 40 patients with chronic stable airflow obstruction (including five with asthma) attending a respiratory outpatient department (table 1 ). They were aged 38-75 years and comprised 11 women and 29 men. All had moderate or severe airflow 
Table 1 Details of patients and normal subjects

\begin{tabular}{|c|c|c|c|c|c|c|}
\hline \multirow[t]{2}{*}{ Group } & & \multirow[t]{2}{*}{ Age (y) } & \multirow[t]{2}{*}{ Height (m) } & $F E V_{1}$ & $F R C$ & $T L C$ \\
\hline & & & & \multicolumn{3}{|c|}{ (\% predicted) } \\
\hline $\begin{array}{l}\text { Patients }(n=40) \\
\text { Normal subjects }(n=20)\end{array}$ & $\begin{array}{l}\text { Range } \\
\text { Mean } \\
\text { SD } \\
\text { Range } \\
\text { Mean } \\
\text { SD }\end{array}$ & $\begin{array}{l}38-75 \\
60 \cdot 9 \\
8 \cdot 6 \\
25-64 \\
42 \cdot 1 \\
11 \cdot 6\end{array}$ & $\begin{array}{l}1 \cdot 48-1 \cdot 86 \\
1 \cdot 66 \\
0 \cdot 10 \\
1 \cdot 58-1 \cdot 89 \\
1 \cdot 73 \\
0.08\end{array}$ & $\begin{array}{l}9-69 \\
28 \cdot 7 \\
11 \cdot 8 \\
95-156 \\
113 \cdot 0 \\
16 \cdot 0\end{array}$ & $\begin{array}{l}116-324 \\
185 \\
49 \cdot 4 \\
89-143 \\
113 \\
11 \cdot 5\end{array}$ & $\begin{array}{l}98-214 \\
134 \\
26 \cdot 0 \\
77-125 \\
108 \\
12 \cdot 8\end{array}$ \\
\hline $\begin{array}{l}\text { Signincance or airrerence between } \\
\text { patients and normal subjects }(p)\end{array}$ & & $<0.01$ & $<0.01$ & $<0.001$ & $<0.001$ & $<0.001$ \\
\hline
\end{tabular}

FRC - forced vital capacity; TLC - total lung capacity.

obstruction with an $\mathrm{FEV}_{1}$ of less than $70 \%$ of the predicted value and hyperinflation with a plethysmographic estimate of functional residual capacity (FRC) exceeding $115 \%$ predicted. The patients were otherwise unselected and, in particular, the presence or absence of abnormal chest wall motion was not a criterion for entry to the study. Three additional patients were excluded, two because of inability to perform the manoeuvre necessary for measurement of thoracic gas volume and one because of persistent movement artefacts on magnetometer records. Twenty normal subjects were also studied to assess the normal relationships between dimensional and volume changes. They had a similar sex distribution to the patients but were on average slightly taller and appreciably younger (table 1).

Before any measurements of chest wall dimensions were made each subject was examined clinically by the same observer in the upright sitting position. Particular attention was paid to the presence of paradoxical motion - that is, movement of an individual dimension of ribcage or abdomen that was of opposite direction to the change in volume.

FEV , and vital capacity (VC) were recorded with a bellows spirometer and functional residual capacity (FRC) and total lung capacity (TLC) were measured in a constant volume body plethysmograph by the method of DuBois et al. ${ }^{6}$ Measurements were expressed as percentages of the predicted values. ${ }^{7}$ From the chest radiograph the curvature of the right diaphragmatic dome was estimated ${ }^{8}$ and total diaphragm length was measured by the method of Braun et al. ${ }^{9}$

Dimensions of the chest wall were measured with four pairs of linearised magnetometers attached to the skin by double sided adhesive tape. The anteroposterior diameter of the ribcage was measured at the level of the 5th intercostal space in the midline and the anteroposterior diameter of the abdomen was measured $2 \mathrm{~cm}$ above the umbilicus. Two lateral diameters were recorded, the upper in the mid-axillary line at the same horizontal level as the anteroposterior diameter and the lower in the mid-axillary line over the costal margin. The signals were recorded on a Lectromed M19 pen recorder. Each pair of magnets was calibrated by a standard electrical signal and the gain on the amplifiers was adjusted to give the desired amplitude for a known displacement; this allowed measurement of both the absolute chest diameter and the change in diameter during breathing for each pair of magnetometers. The instruments were linear over the range 15$50 \mathrm{~cm} .{ }^{10}$ Measurements were made in the upright position with the subject seated in a pressure compensated variable volume plethysmograph" so that change in thoracic gas volume could be recorded simultaneously. The subject was made as comfortable as possible and was asked to sit upright with the spine in contact with the posterior wall of the plethysmograph. After the subject was settled and breathing steadily a recording at fast paper speed was made, from which at least five representative breaths were analysed.

Individual breaths were examined by plotting dimensional changes as a function of change in lung volume on a digitising tablet and offline microcomputer. Paradoxical motion was identified by a change in any dimension of opposite polarity to the similtaneous change in lung volume. For each subject the differences in each dimension between end expiration and end inspiration were averaged over five breaths.

In 20 patients recordings were also made outside the plethysmograph with each subject sitting, supine, and reclining at $45^{\circ}$. In these studies anteroposterior abdominal diameter was used to indicate the phase of respiration. This subgroup of patients did not include any with anteroposterior abdominal paradox. In five of the patients the addition of a Fleisch pneumotachograph at the mouth confirmed the validity of using the anteroposterior abdominal diameter to define the onset of inspiration and expiration.

Measurements were repeated in 16 patients after an interval of 10 days to 10 months and in three 
patients the measurements were made on three occasions.

Any differences between groups of subjects were identified by analysis of variance and comparisons between the patients and normal subjects were made using Student's $t$ test. For each patient the relationships between tidal displacement of each dimension and indices of airflow obstruction $\left(\mathrm{FEV}_{1}\right)$ and of hyperinflation (FRC) were analysed by linear regression; a correlation matrix of dimensional changes against four variables-age, symptom dura- tion, $\mathrm{FEV}_{1}$, and $\mathrm{FRC}$ (\% predicted)-was also used in a multiple regression to calculate the partial correlation coefficients for each when the other three were held constant.

\section{Results}

\section{PATTERNS OF ABNORMALITY RECORDED BY MAGNETOMETRY}

In all the normal subjects during tidal breathing movement of all four diameters was always closely related to volume change and no paradoxical motion

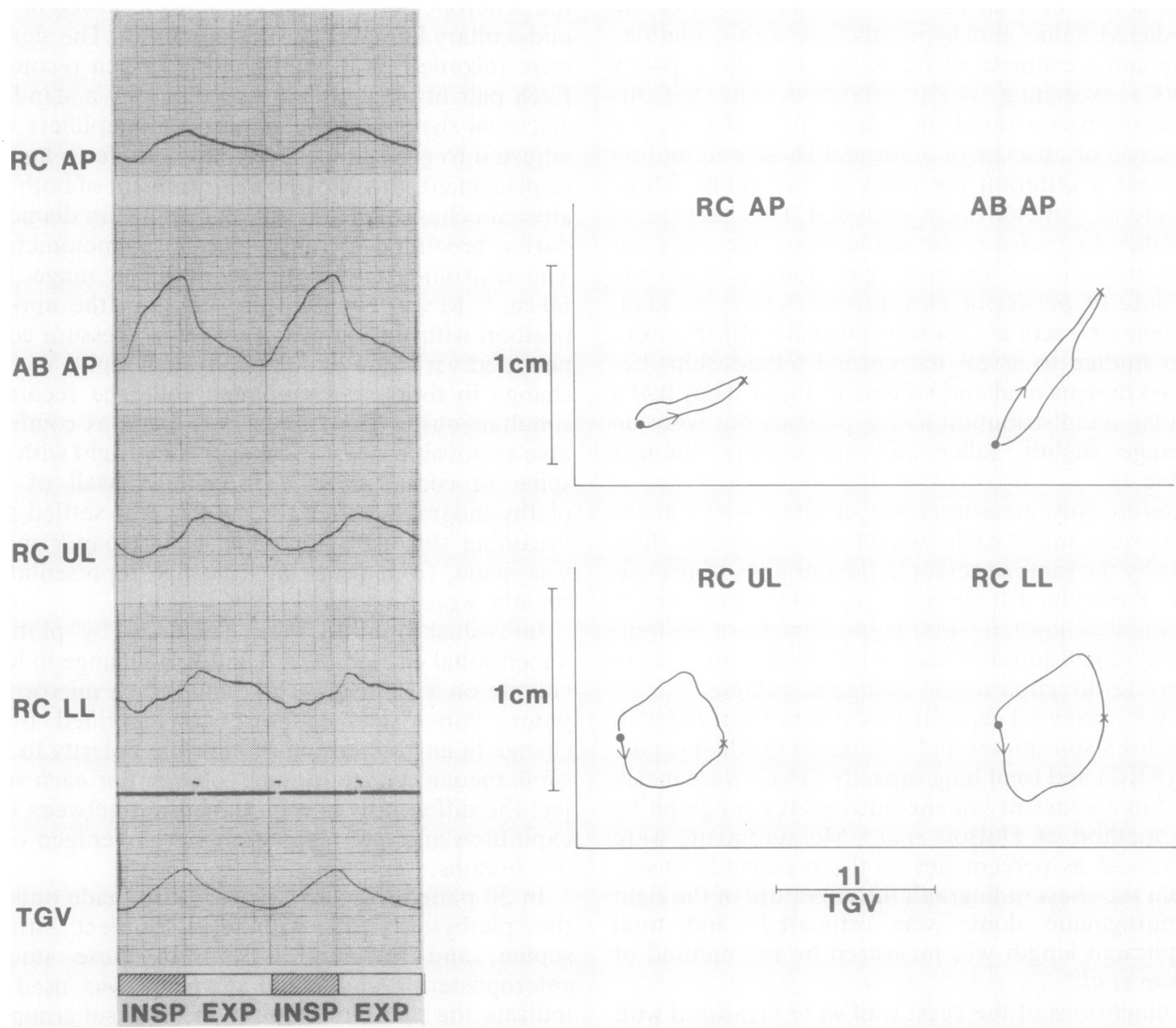

Fig 1 Typical lateral ribcage paradox. The left hand panel shows two tidal breaths from a patient with typical lateral ribcage paradox. Three ribcage dimensions, the abdominal anteroposterior dimension $(A B A P)$, and change in lung volume (TGV) are displayed against time. RCAP -ribcage anteroposterior; $R C U L \longrightarrow$ ribcage upper lateral; $R C$

$L L \longrightarrow$ ribcage lower lateral. The right hand panel shows each dimension plotted against $T G V$ for one tidal breath with end expiration (O) and end inspiration $(\times)$ indicated. Note that whereas $R C A P$ and $A B A P$ increase and decrease in phase with volume, both lateral dimensions decrease in inspiration. The paradoxical motion begins at onset of inspiration and the dimension starts to increase before end inspiration. During the first half of expiration the lateral dimension paradoxically increases. 

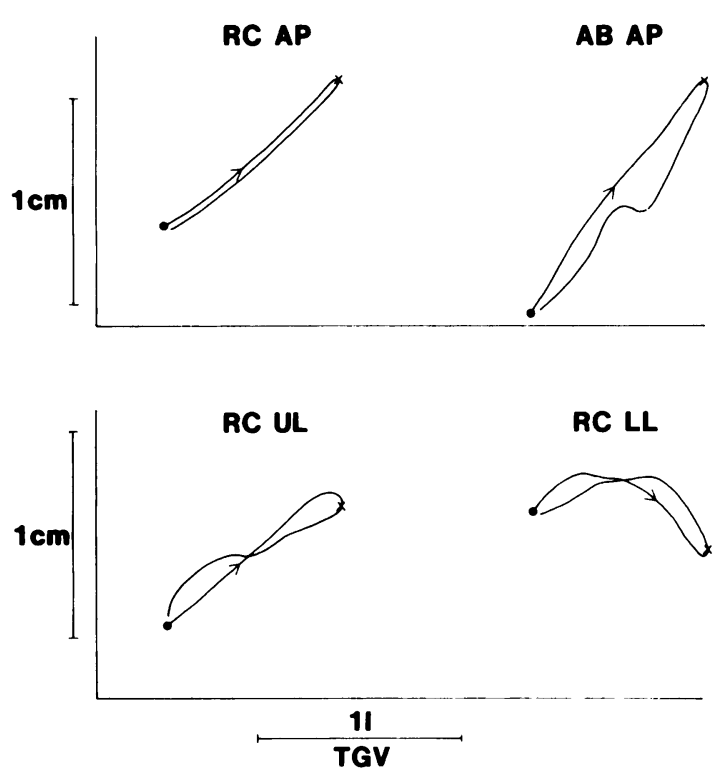

Fig 2 Late inspiratory lateral ribcage paradox (display and calibrations as in fig 1, right hand panel; abbreviations as in fig 1). RC LL increases normally for the first $150 \mathrm{ml}$ of tidal volume, only to decrease in the later part of inspiration. This "atypical" timing was seen in six of the 31 patients with lateral paradox. was seen. Of the 40 patients, only five had qualitatively normal chest wall motion and 35 had clear abnormalities; in 13 of these patients abnormal motion was noted in two or more dimensions. The following types of abnormality were identified:

\section{Lateral ribcage paradox}

Lateral ribcage paradox was seen in 31 of the 40 patients. Typically it began with the onset of inspiration with a decrease in diameter as lung volume increased and usually some increase in diameter occurred towards the end of inspiration; the dimension then paradoxically increased in the first part of expiration (fig 1). In most patients paradoxical motion was seen at both lower and upper ribcage levels; it was usually greater at the lower level, but in six patients the inspiratory reduction in lateral dimension was greater at the upper level.

In six of the 31 patients the timing of the paradoxical motion of the lower lateral ribcage diameter was different in that the dimension increased in early inspiration only to decrease towards the end of inspiration (fig 2). Three other patients had a combination of late inspiratory paradox at the upper level and of more typical early inspiratory paradox at the lower level.

In three patients paradoxical motion was intermittent; in one this may have been related to the size of
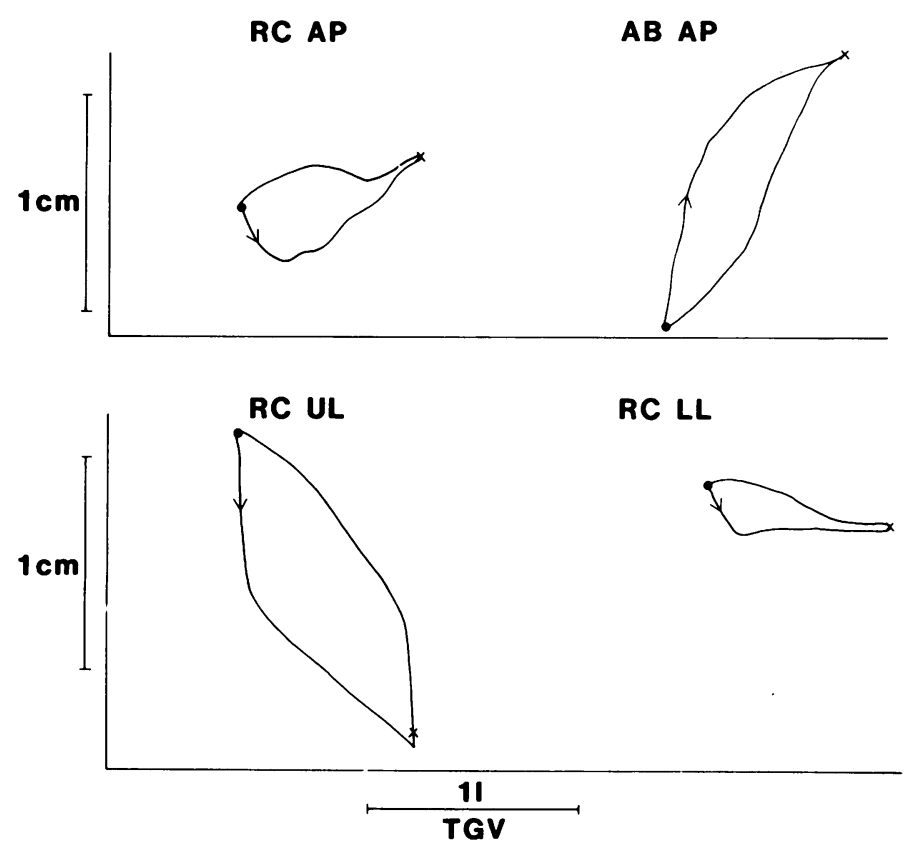

Fig 3 Paradox of anteroposterior diameter of ribcage (display and abbreviations as in fig 1). Note the decrease in RC AP at the beginning of inspiration, the dimension increasing in size midway through the breath. There is also inspiratory and expiratory lateral ribcage paradox, which in this patient is more noticeable at the upper level. 

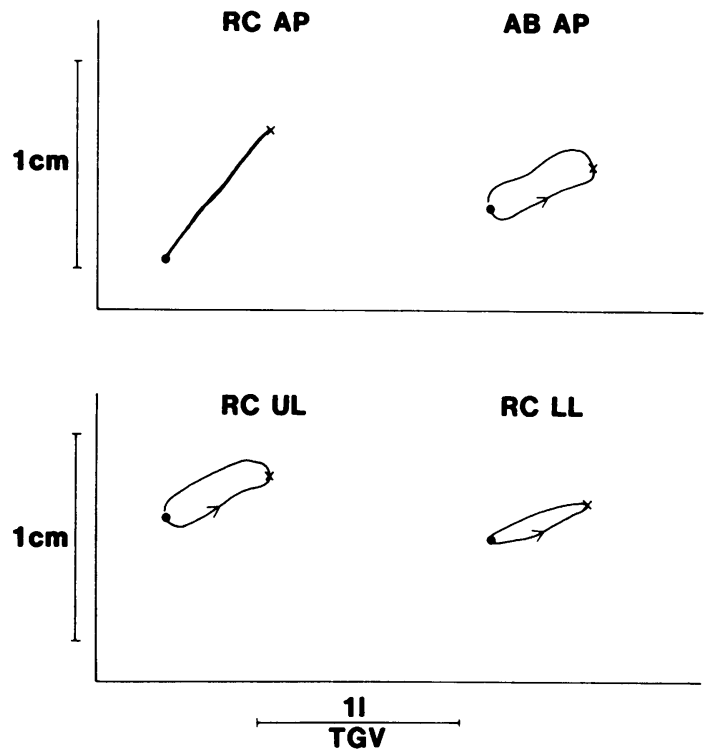

Fig 4 Paradoxical abdominal motion (display and abbreviations as in fig 1). There is slight indrawing of the $A B$ AP diameter during early inspiration. This contrasts with the usual increase in abdominal size as lung volume increases ( $c f$ figs $1,2,3,5$ ).

the tidal volume but in the other two no obvious explanation was apparent. Sixteen patients with lateral paradox had repeat studies and the abnormality persisted in 15 . In the other patient the abnormality was no longer apparent even though there had been no recognisable change in lung function.

Of the 31 patients with lateral paradox, measurements were made in the supine position in 16. The paradox disappeared or was less noticeable in 10 patients; in three there was no change and in three the paradox increased.

\section{Anteroposterior ribcage paradox}

Inspiratory indrawing of the lower sternum (fig 3) was recorded in 12 patients. It typically occurred very early in inspiration and the diameter was always increasing by mid-inspiration. In two subjects the abnormality was intermittent during the recording, and when restudied two other patients out of nine no longer showed it. Five patients with anteroposterior paradox were also studied supine and paradoxical motion was still present. In most instances anteroposterior ribcage paradox was seen in patients who also showed lateral paradox (as in fig 3) but in two patients it was the solitary abnormality.

\section{Abnormal abdominal motion}

Abnormalities of abdominal motion were recorded in 10 patients. In four there was a slight reduction in the anteroposterior abdominal dimension at the onset of inspiration (fig 4). In six patients the abnormal anteroposterior diameter showed a biphasic expiratory pattern: after qualitatively normal motion during inspiration, the dimension declined rapidly at the onset of expiration and then either it increased in size again or its rate of decline
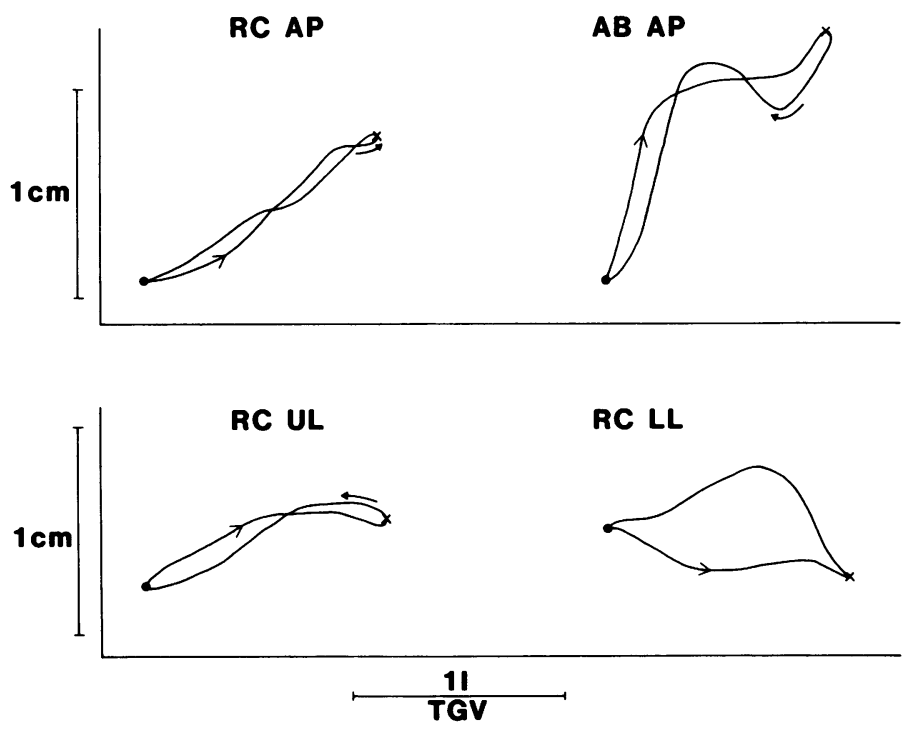

Fig 5 Biphasic expiratory abdominal movement (display and abbreviations as in $f g$ 1). During inspiration $A B A P$ increases with volume. At the beginning of expiration the abdominal dimension decreases but then increases again before declining to its FRC value. There is also late inspiratory paradox of RCUL and paradox of RCLL through most of inspiration. 
Table 2 Chest wall dimensions in patients and normal subjects sitting upright

\begin{tabular}{|c|c|c|c|c|c|c|c|c|c|c|c|}
\hline \multirow[t]{2}{*}{ Group } & & \multicolumn{4}{|c|}{ Absolute dimensions ( $\mathrm{mm}$ ) at FRC } & \multirow{2}{*}{$\begin{array}{l}\text { Ratio } \\
\text { RCUL: } \\
\text { RCAP }\end{array}$} & \multirow{2}{*}{$\begin{array}{l}\text { Tidal } \\
\text { volume }(l)\end{array}$} & \multicolumn{4}{|c|}{ Tidal change in dimensions ( $\mathrm{mm}$ ) } \\
\hline & & $R C A P$ & $A B A P$ & $R C U L$ & $R C L L$ & & & $R C A P$ & $A B A P$ & $R C U L$ & $R C L L$ \\
\hline \multirow{2}{*}{\multicolumn{2}{|c|}{$\begin{array}{ll}\text { Patients } & \begin{array}{l}\text { Mean } \\
\text { SD }\end{array} \\
\text { Normal subjects } & \text { Mean } \\
\text { SD }\end{array}$}} & $\begin{array}{c}251 \\
34 \\
231 \\
28.7\end{array}$ & $\begin{array}{c}252 \\
50 \cdot 3 \\
252 \\
38.7\end{array}$ & $\begin{array}{c}293 \\
33 \cdot 1 \\
303 \\
24 \cdot 1\end{array}$ & $\begin{array}{c}290 \\
28 \cdot 3 \\
292 \\
25 \cdot 4\end{array}$ & $\begin{array}{l}1 \cdot 18 \\
0.12 \\
1.32 \\
0.02\end{array}$ & $\begin{array}{l}0.75 \\
0.22 \\
0.75 \\
0.27\end{array}$ & $\begin{array}{l}4 \cdot 4 \\
1.6 \\
4 \cdot 1 \\
1 \cdot 3\end{array}$ & $\begin{array}{l}7 \cdot 6 \\
3 \cdot 9 \\
6 \cdot 2 \\
4 \cdot 7\end{array}$ & $\begin{array}{l}0.7 \\
4 \cdot 3 \\
3 \cdot 7 \\
2 \cdot 3\end{array}$ & $\begin{array}{r}-0.5 \\
3.7 \\
4.1 \\
1.8\end{array}$ \\
\hline & & $<0.05$ & NS & NS & NS & $<0.001$ & NS & NS & NS & $<0.01$ & $<0.001$ \\
\hline
\end{tabular}

RC AP-ribcage anteroposterior; AB AP-abdomen anteroposterior; RC UL-ribcage upper lateral; RC LL-ribcage lower lateral;

NS-not significant.

became much slower (figs 2 and 5). Three subjects were studied in the supine posture and in each the abnormal movement was still present.

Lateral paradox of the ribcage was apparent on physical examination in all except one of the patients in whom it was subsequently demonstrated by magnetometry; in two other patients lateral ribcage paradox was thought to be present on clinical examination but it was not confirmed by magnetometry, although one of these subjects did show anteroposterior ribcage paradox. In no patient was anteroposterior paradox of the ribcage or abnormal motion of the abdomen detected clinically.

\section{QUANTITATIVE FINDINGS}

The absolute dimensions at FRC for normal subjects and patients are shown in table 2 . The ribcage

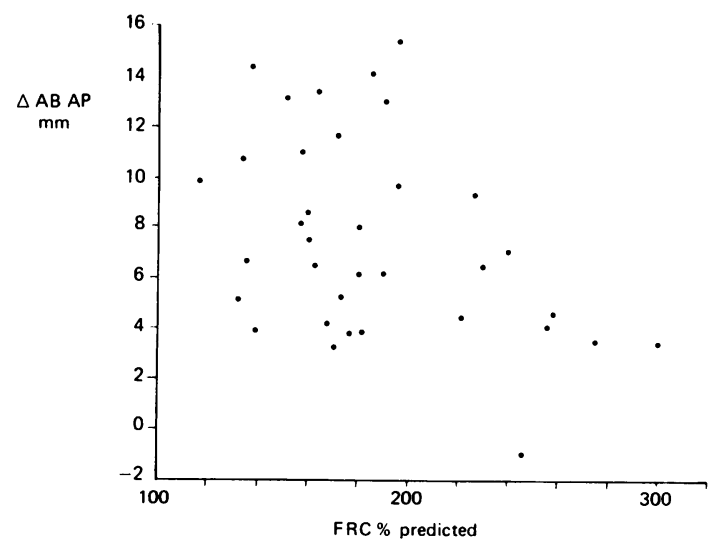

Fig 6 Relationship between tidal abdominal excursion $(\triangle A B A P)$ and degree of hyperinflation (FRC \% predicted). There is a negative correlation $(r=-0.41, p<0.02)$ and the relationship still holds (partial correlation coefficient $r=$ $-0.39, p<0.02$ ) when airflow obstruction, age, and symptom duration are allowed for. anteroposterior diameter was significantly greater in the patients and comparison of the lateral and anteroposterior dimensions at the upper ribcage level confirmed the clinical impression that the ribcage is more circular in cross section in such patients than in normal subjects.

Table 2 also shows the average difference in each of the four dimensions between end expiration and end inspiration in the patients and normal subjects in the upright position. Anteroposterior motion was similar in the two groups but the lateral displacements were less in the patients and the overall mean change at the lower level in the patients was negative. There was no significant difference in mean tidal volume between the patients and normal subjects.

Analysis of variance showed no significant differences in the severity of airflow obstruction or hyper-

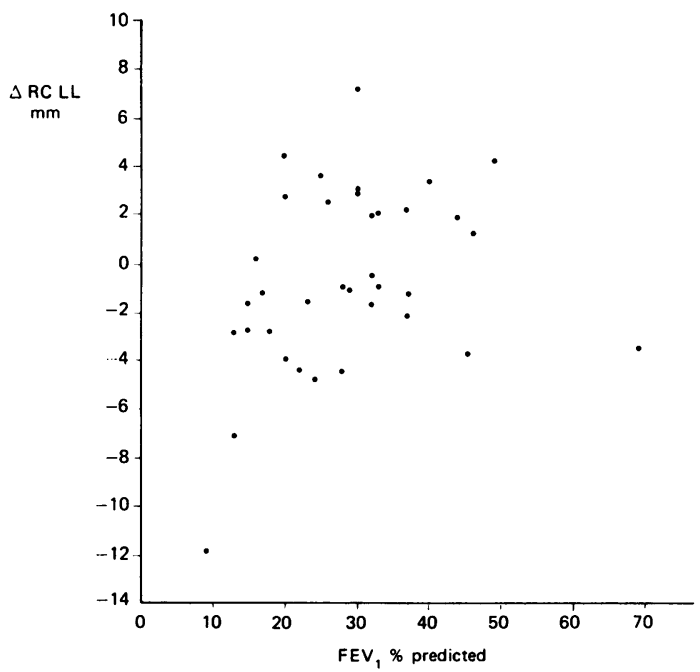

Fig 7 Relationship of lower lateral ribcage movement $(\triangle R C L L)$ to severity of airflow obstruction (indicated by $F E V$ \% predicted). There is a weak correlation $(r=0 \cdot 36, p$ $<0.05)$ and the trend is still significant when FRC, age, and symptom duration are allowed for (partial correlation coefficient $r=0.35, p<0.05$ ). 
inflation between those patients with normal chest wall motion and those with particular types of abnormal motion. The relationships between displacement of each diameter and the severity of airflow obstruction and of hyperinflation were examined by plotting dimensional change against FEV $_{1}$ and FRC respectively (both expressed as percentages of predicted values). Correlations were generally weak but there was a tendency for patients with the greatest FRC to have the least abdominal motion $(\mathrm{r}=-0.41, \mathrm{p}<0.02$; fig 6$)$ and for those with the most severe airflow obstruction to have the least displacement of low lateral ribcage diameter ( $r$ $=0.36, p<0.05$, fig 7). Multiple regression analysis showed that these relationships with FRC and with $\mathrm{FEV}_{1}$ were still significant after the other variables included in the contingency tables had been taken into account. The tidal differences in individual chest wall dimensions did not show a significant correlation with either of the two radiological indices of diaphragmatic length and shape.

\section{Discussion}

We found a very high frequency of abnormal chest wall motion in this group of patients with severe chronic airflow obstruction and hyperinflation. We have confirmed that lateral indrawing of the ribcage is the commonest abnormality. We found that this was nearly always recognisable by careful observation, but recognition may have been aided by a learning effect as the study progressed. We did not compare different observers, and recognition of lateral paradox is known to vary between observers. ${ }^{12}$ It is also possible that at $45^{\circ}$, the usual position for clinical examination, lateral ribcage indrawing may be overlooked as in some patients in this study it was then less evident than in the upright position. Although it is a valuable guide to the presence of airways obstruction, its value as a quantitative index is very limited as we found only a weak correlation between reduction in $\mathrm{FEV}_{1}$ and lateral ribcage motion and there was no clear level of airflow obstruction above which this abnormality did not occur. The multiple regression analysis confirmed that this relationship between worsening $\mathrm{FEV}_{1}$ and decreasing lower lateral ribcage motion was independent of the degree of hyperinflation. Stubbing et $\mathrm{l}^{13}$ found that lateral paradox (based on a simple grading of the physical sign) correlated with $\mathrm{FEV}_{1}$ and age, but no relationship with age or duration of symptoms was found in our patients.

Other abnormalities of chest wall motion were less common and more subtle and not readily detectable clinically even though the observer was aware of their possibility. The early inspiratory paradox of the lower sternum has some similarities to the abnormal motion recorded in normal subjects during severely loaded breathing ${ }^{14}$ and perhaps to the more easily detectable indrawing seen in children with croup. In our patients the abnormality tended to be more evanescent than lateral paradox. Its different timing suggests a different mechanism, although some patients showed both types of abnormality.

Paradoxical motion of the abdominal wall has been described in various conditions, including diaphragmatic weakness ${ }^{15}$ and fatigue; ${ }^{16}$ it was also noted by Sharp et $a l^{3}$ in chronic airways obstruction but their patients were acutely ill. Although not detected clinically in our patients, abdominal paradox was recorded at the onset of inspiration in four patients. A reduction in tidal abdominal displacement was common and there was an inverse relationship between the severity of hyperinflation and anteroposterior motion of the abdomen during a tidal breath; this was independent of the severity of airflow obstruction and presumably reflects an inability of the flattened diaphragm to displace the abdominal contents forward. The biphasic pattern of abdominal motion seen in six patients is somewhat similar to that described by Ashutosh et al ${ }^{4}$ in acutely ill patients with respiratory failure and may represent a milder form of the same abnormality.

Unlike Brennan et al, ${ }^{17}$ we found no difference in the tidal excursion of the anteroposterior dimension of the ribcage between the patients and normal subjects. The age difference between our two groups of subjects is unlikely to have influenced this comparison since age has little effect on the anteroposterior motion of the chest wall in normal subjects. ${ }^{18}$ Since, however, the geometry of the chest wall varied between the subjects the relationships of individual displacements to volume change will also have been different. We have attempted to take account of differences between subjects in both the size of the tidal volume and the absolute dimensions by correcting the tidal changes according to various mathematical models relating dimensional and volume changes. No correction for absolute dimension or tidal volume was found which would improve the weak relationships between linear displacements and FEV, or FRC. Possibly, however, airways resistance during tidal breathing would give a more relevant index of the appropriate load and might show a better correlation with dimensional changes.

Lateral ribcage paradox is generally assumed to be caused by diaphragmatic contraction because of the abnormal orientation of the fibres in the overinflated chest. Although we found no relationship between radiographic estimates of diaphragm length or configuration and dimensional changes, 
the indices from the chest radiograph were taken from routine films at full inspiration and may not therefore be the most appropriate for comparison with measurements during tidal breathing. The relationship of lateral ribcage paradox to diaphragmatic activity is supported by transdiaphragmatic pressure measurements. ${ }^{19}$ It has been suggested that paradox of the ribcage in the anteroposterior dimension is related to abdominal muscle relaxation at the onset of inspiration..$^{5}$ Both paradoxical and "incoordinate" abdominal motion have been attributed to ineffectual diaphragmatic contraction, ${ }^{34}$ but abdominal muscle activity may again play a role.

In conclusion, we have confirmed a very high frequency of abnormalities of chest wall motion in patients with severe airflow obstruction and hyperinflation. Lateral paradox of the ribcage (Hoover's sign) was the commonest and clinically the most easily recognisable abnormality in this series. Other patterns of abnormal motion are also common but difficult to recognise clinically. In general, patients with more severe airflow obstruction have less motion of the lateral ribcage and those with the more severe degrees of hyperinflation have less abdominal motion.

Thanks are due to Dr S Nariman for allowing us to study patients under his care, to Mrs T Small and Mrs Y Ferguson for technical assistance, and to Mrs B Wears for typing the manuscript. Mr RA McNay helped with the statistical analysis. We are also grateful to Mr CJ Griffiths and the department of medical physics, Freeman Hospital, who built the magnetometry equipment. Dr JJ Gilmartin was the recipient of a research grant from the Northern Regional Health Authority during this work.

\section{References}

' Hoover CF. The diagnostic significance of inspiratory movements of the costal margins. Am J Med Sci 1920;159:633-46.

${ }^{2}$ Campbell EJM. Physical signs of diffuse airways obstruction and lung distension. Thorax 1969;24:1-3.

${ }^{3}$ Sharp JT, Goldberg NB, Druz WS, et al. Thoracoabdominal motion in chronic pulmonary disease. Am Rev
Respir Dis 1977;115:47-56.

${ }^{4}$ Ashutosh K, Gilbert R, Auchincloss JH, Peppi D. Asynchronous breathing movements in patients with chronic obstructive pulmonary disease. Chest 1975;67:553-7.

${ }^{5}$ Gibson GJ, Pride NB, Clark E. Function of the diaphragm in patients with severe hyperinflation. Am Rev Respir Dis 1979;119:175-7.

- DuBois AB, Botelho SY, Bedell GN, et al. A rapid plethysmographic method for measuring thoracic gas volume: a comparison with a nitrogen washout method for measuring functional residual capacity in normal subjects. J Clin Invest 1956;35:322-6.

${ }^{7}$ Cotes. JE. Lung function: assessment and application in medicine. 4th ed. Oxford: Blackwell Scientific Publications, 1979.

${ }^{8}$ Simon G. Principles of chest $x$-ray diagnosis. 4th ed. London: Butterworth, 1978.

${ }^{9}$ Braun NMT, Arora NS, Rochester DF. Force-length relationship of the normal human diaphragm. J Appl Physiol 1982;53:405-12.

${ }^{10}$ Griffiths CJ, Gilmartin JJ, Gibson GJ, Murray A. Measurement of chest wall movement: design performance and clinical use of a four channel magnetometer instrument. Clin Phys Physiol Meas 1983;4:363-71.

"Stanescu DC, De Sutter P, Van de Woestijne KP. Pressure-corrected flow body plethysmograph. Am Rev Respir Dis 1972;105:304-5.

${ }^{12}$ Godfrey S, Edwards RHT, Campbell EJM, et al. Repeatability of physical signs in airways obstruction. Thorax 1969;24:4-9.

${ }^{13}$ Stubbing DG, Mathur PN, Roberts RS, Campbell EJM. Some physical signs in patients with chronic airflow obstruction. Am Rev Respir Dis 1982;125:549-52.

${ }^{14}$ Agostini E, Mognoni P. Deformation of the chest wall during breathing efforts. J Appl Physiol 1966;21:1827-32.

${ }^{15}$ Mortola JP, Sant Ambrogio G. Motion of the rib cage and abdomen in tetraplegic patients. Clin Sci 1978;54:25-32.

${ }^{16}$ Roussos C, Fixley M, Gross D, Macklem PT. Fatigue of inspiratory muscles and their synergic behaviour. $J$ Appl Physiol 1979;46:897-904.

${ }^{17}$ Brennan NJ, Morris AJR, Green M. Thoracoabdominal mechanics during tidal breathing in normal subjects and in emphysema and fibrosing alveolitis. Thorax 1983;38:62-6.

${ }^{18}$ Sharp JT, Goldberg NB, Druz WS, Danon J. Relative contributions of rib cage and abdomen to breathing in normal subjects. J Appl Physiol 1975;39:608-18.

${ }^{19}$ Gilmartin JJ, Gibson GJ. Mechanisms of paradoxical lateral ribcage motion in patients with airflow obstruction. Thorax 1983;38:711 (abstract). 